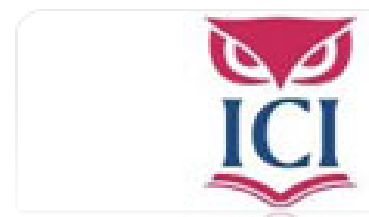

IUS. Revista del Instituto de Ciencias Jurídicas de Puebla A.C.

ISSN: 1870-2147

revista.ius@hotmail.com

Instituto de Ciencias Jurídicas de Puebla A. C.

México

Talavera, Pedro

El derecho europeo ante el matrimonio y las uniones de hecho de personas del mismo sexo IUS. Revista del Instituto de Ciencias Jurídicas de Puebla A.C., núm. 20, 2007, pp. 6-25 Instituto de Ciencias Jurídicas de Puebla A. C.

Puebla, México 


\title{
EL DERECHO EUROPEO ANTE EL MATRIMONIO Y LAS UNIONES DE HECHO DE PERSONAS DEL MISMO SEXO
}

Pedro Talavera*

\author{
SUMARIO \\ I. Primera etapa: despenalización de las relaciones homosexuales \\ II. Segunda ETAPa: LA LUCHA CONTRA LA DISCRIMINACIÓN \\ II.I LA DOCTRINA DE LA DISCRIMINACIÓN POR RAZÓN DE ORIENTACIÓN SEXUAL \\ II.II TRANSEXuales frente al Matrimonio \\ III. Tercera etapa: el reconocimiento Juridico de las uniones afectivas homosexuales \\ III.I. La Resolución 28/1994 del Parlamento Europeo \\ III.II. ReConocimiento JuRídico de LA unión Afectiva homosexual \\ III.II.I. PAISES SIN REGULACIÓN \\ III.II.II. Paises que han aprobado leyes de parejas de hecho \\ III.II.II. Paises que han aprobado leyes de uniones Civiles homosexuales \\ iv. Cuarta etapa: apertura del matrimonio a personas del mismo seXo \\ V. LA ADOPCIÓN: UN PROBLEMA COMPLEJO \\ VI. Consideraciones finales
}

\section{RESUMEN}

En la práctica totalidad de los paises europeos las uniones de personas del mismo sexo han adquirido un reconocimiento jurídico que, en Holanda, Bélgica y España, llega hasta la posibilidad de acceder al matrimonio. El presente artículo analiza las cuatro etapas fundamentales y sucesivas que se han superado hasta conseguir este objetivo y el importante papel que en ello han tenido algunas resoluciones importantes del Tribunal Europeo de Derechos Humanos. Se analizan también las diversas figuras que cada pais ha puesto en marcha para implementar dicho reconocimiento jurídico.

\section{ABSTRACT}

In the majority of the European countries the couples of the same sex people have acquired a juridical recognition that, in Holland, Belgium and Spain, it arrives until the possibility of consenting to the marriage. The present article analyzes the four fundamental and successive stages that have been overcome until getting this objective and the important paper that in they have had it some important resolutions of the European Court of Human Rights. They are also analyzed the diverse figures that each country has started to implement this juridical recognition.

* Profesor titular de filosofía del derecho, Universidad de Valencia, España. 
La institucionalización jurídica de las uniones homosexuales, en la práctica totalidad de los países europeos, ha seguido un guión bien definido en cuanto al itinerario a recorrer y al orden en el que plantear las batallas jurídicas. Este itinerario normalizador y equiparador de las uniones de personas del mismo sexo al matrimonio responde a una especie de "hoja de ruta" con cuatro etapas fundamentales y sucesivas: a) la despenalización de las relaciones homosexuales; b) la lucha contra la discriminación y por la normalización social; c) el reconocimiento jurídico de las uniones afectivas homosexuales; d) la apertura del matrimonio a las personas del mismo sexo.

En el ámbito europeo, todos los países han recorrido ya las dos primeras etapas, que se han producido como consecuencia de importantes resoluciones del Tribunal Europeo de Derechos Humanos. A ellas dedicaremos la primera parte de este trabajo. Quedan algunos países por consolidar la tercera etapa (además de los diez nuevos miembros de la uE), pero están en vías de hacerlo. Y sólo dos países, además de España, ${ }^{1}$ se han situado en la cuarta etapa. Lo analizaremos en la segunda parte de este estudio.

\section{Primera etapa: despenalización de las relaciones homosexuales}

Las relaciones homosexuales estuvieron tipificadas como delito en la mayoría de los países europeos hasta fechas bien recientes. La propia jurisprudencia del Tribunal Europeo de Derechos Humanos (TEDH), hasta principios de los años ochenta, vino a confirmar la legitimidad de dicha tipificación penal. Podrían distinguirse dos fases en la posición de los órganos de Estrasburgo. ${ }^{2}$ En la primera, hasta principios de los años ochenta, la Comisión de Derechos Humanos rechazó las demandas presentadas por homosexuales contra distintos aspectos de la criminalización de la homosexualidad en legislaciones nacionales de estados miembros. Podríamos tomar como representativas de esta fase dos decisiones: La Decisión 104/55, de 17 de diciembre de $1955^{3}$ y la Decisión 5935/75, de 30 de septiembre de $1975 .{ }^{4}$

\footnotetext{
1 Para estudiar a fondo la reforma que se ha producido en España, a raíz de las leyes 13 y 15/2005, por las que se modifica el Código Civil en materia de derecho a contraer matrimonio y de separación y divorcio, y en la que se incluye en el concepto de matrimonio a cualesquiera dos personas con independencia de su sexo, remito al interesante artículo publicado por S. Carrión Olmos, "Reflexiones de urgencia en torno a las leyes 13 y 15/2005 por las que se modifica el Código Civil en materia de separación y divorcio y derecho a contraer matrimonio", diario La Ley, No. 6298, 19 de julio de 2005, pp. 1-5.

${ }^{2}$ Seguimos en este punto la distinción apuntada por R. Navarro Valls, Matrimonio y derecho, Tecnos, Madrid 1995, pp. 91-94.

${ }^{3}$ Cfr. Decisión 104/55, Annuaire de la Convention européenne des droits de l'homme, 1955-1957, pp. 228-229.

${ }^{4}$ Cfr. Decisión 5935/72, Commision européenne des droits de l’homme, Décisions et rapports, Vol.
} 
El cambio de orientación en la jurisprudencia de Estrasburgo, que dio lugar a la despenalización de las relaciones homosexuales en el ámbito europeo, se produce en los años ochenta a partir de la emblemática sentencia del TEDH dictada en el caso Dudgeon, con fecha de 22 octubre de $1981 .{ }^{5} \mathrm{El}$ Tribunal de Estrasburgo, aun reconociendo legítima una cierta reglamentación penal de la homosexualidad masculina, concluye por mayoría que Dudgeon (un homosexual irlandés detenido por esta práctica) ha sufrido un atentado contra su vida privada. Pero rechaza que tenga derecho a practicar la homosexualidad con menores de veintiún años y reafirma el derecho de los estados miembros del Consejo de Europa a regular penalmente la homosexualidad, en la medida que sea necesario para defenderse contra la explotación y la corrupción de personas especialmente vulnerables. No obstante, un año después de la sentencia (9 de diciembre de 1982), Irlanda del Norte despenalizaba los actos homosexuales entre adultos a partir de los veintiún años. ${ }^{6}$

Esta decisión encontró eco en la Recomendación 924 (1981) de la Asamblea Parlamentaria del Consejo de Europa, que solicitó al Consejo de Ministros una exhortación a los estados miembros dirigida a abolir las leyes que sancionaran penalmente la homosexualidad. ${ }^{7}$ Dicha resolución incluía, además, una invitación a la Organización Mundial de la Salud tendente a eliminar la homosexualidad de la Clasificación Internacional de Enfermedades. Esta supresión se produjo el 1 de enero de 1993 (en la ICD-10). ${ }^{8}$ Esa

3, pp. 46-51. Un análisis más extenso del caso, con referencia al caso Norris, puede verse en N. Pérez Cánovas, Homosexualidad, homosexuales y uniones homosexuales en el derecho español, Comares, Granada, 1994, pp. 53-61.

${ }^{5}$ Sent Dudgeon, en Publications de la Cour européenne des droits de l'homme, Serie A, § 45ss.

${ }^{6}$ Cfr. J. B. Marie, L'homosexualité et la Convention européenne des droits de l'homme, en el Vol. "L'homosexuel (le) dans les societés civiles et religieuses", Strasbourg 1985, pp.61ss.

${ }^{7}$ La resolución contenía, entre otras, las siguientes recomendaciones: Aplicar la misma edad de consentimiento para las relaciones heterosexuales y homosexuales; destrucción de las fichas y datos especiales relativos a homosexuales por parte de la policía u otros organismos; asegurar una igualdad de tratamiento a los homosexuales en materia laboral, de remuneración y seguridad en el trabajo, especialmente en el sector público; pedir la interrupción de todo tratamiento obligatorio dirigido a modificar la orientación sexual de los adultos; eliminación de toda discriminación en la tutela o el régimen de visitas a los hijos respecto a los padres por su orientación homosexual; pedir a los responsables administrativos y a las autoridades públicas la prevención de todo riesgo de violación o de abusos sexuales en las cárceles. Cfr. J. B. Marie, L'homosexualité et la Convention européenne des droits de l'homme, Op. cit., p. 80. ${ }^{8}$ En esa misma sesión fue rechazada por la Asamblea de parlamentarios otra propuesta de resolución, solicitando al comité de ministros la modificación del art. 14 de la Convención, en el sentido de "añadir la noción de tendencia sexual". Este artículo, como es sabido, establece el principio de igualdad y no discriminación en los derechos reconocidos por el Convenio de Roma, prohibiendo toda distinción "basada especialmente en el sexo, la raza, el color, la lengua, la religión, las opiniones políticas o de cualquier otro tipo, el origen nacional o social, la pertenencia a una minoría nacional, la fortuna, el nacimiento o cualquier otra circunstancia”. Cfr. N. Pérez Cánovas, Homosexualidad, homosexuales y 
recomendación supuso el primer reconocimiento jurídico internacional del derecho a tener una orientación homosexual y a no ser discriminado por ello. A partir de ese momento desaparecen en Europa todas las legislaciones penalizadoras y el fenómeno comienza a ganar espacio social y jurídico.

Fuera del ámbito regional de acción del Convenio Europeo, el Comité de Derechos Humanos de Naciones Unidas, en su Comunicación de 25 de diciembre de 1991, en el caso Toonen vs. Australia entendió que el artículo 17.1 del Pacto Internacional de Derechos Civiles y Políticos, de 19 de diciembre de 1966, ${ }^{9}$ amparaba los actos homosexuales bajo la protección de la vida privada. ${ }^{10}$

\section{Segunda etapa: la lucha contra la discriminación}

Una vez asentada la doctrina despenalizadora de las relaciones homosexuales, la "hoja de ruta" acomete una segunda etapa: la progresiva eliminación de discriminaciones en todos los ámbitos y la adquisición de un estatus de igualdad. Es a partir de finales de los ochenta del siglo pasado, cuando diversos estados comienzan a introducir disposiciones tendentes a evitar la violencia homófoba, considerándola agravante de determinados delitos. ${ }^{11}$ A finales de los noventa se aprobaron las primeras leyes específicas dirigidas a evitar la discriminación del trabajador homosexual en Dinamarca (1996) ${ }^{12}$ y en Suecia (1999). ${ }^{13}$

uniones homosexuales en el derecho español, Op. cit., pp. 40-41 y 47-49.

${ }^{9}$ La resolución contenía, entre otras, las siguientes recomendaciones: Aplicar la misma edad de consentimiento para las relaciones heterosexuales y homosexuales; destrucción de las fichas y datos especiales relativos a homosexuales por parte de la policía u otros organismos; asegurar una igualdad de tratamiento a los homosexuales en materia laboral, de remuneración y seguridad en el trabajo, especialmente en el sector público; pedir la interrupción de todo tratamiento obligatorio dirigido a modificar la orientación sexual de los adultos; eliminación de toda discriminación en la tutela o el régimen de visitas a los hijos respecto a los padres por su orientación homosexual; pedir a los responsables administrativos y a las autoridades públicas la prevención de todo riesgo de violación o de abusos sexuales en las cárceles. Cfr. J. B. Marie, L'homosexualité et la Convention européenne des droits de l'homme, Op. cit., p. 80. ${ }^{10}$ En esa misma sesión fue rechazada por la Asamblea de parlamentarios otra propuesta de Resolución, solicitando al comité de ministros la modificación del art. 14 de la Convención, en el sentido de "añadir la noción de tendencia sexual”. Este artículo, como es sabido, establece el principio de igualdad y no discriminación en los derechos reconocidos por el Convenio de Roma, prohibiendo toda distinción "basada especialmente en el sexo, la raza, el color, la lengua, la religión, las opiniones políticas o de cualquier otro tipo, el origen nacional o social, la pertenencia a una minoría nacional, la fortuna, el nacimiento o cualquier otra circunstancia”. Cfr. N. Pérez Cánovas, Homosexualidad, homosexuales y uniones homosexuales en el derecho español, Op. cit., pp. 40-41 y 47-49.

${ }^{11}$ En Europa estos países fueron: Noruega (1981), Suecia y Dinamarca (1987), Irlanda y Holanda (1989).

${ }^{12}$ Consultar Informe Ilga-Europa, Bruselas, 1998, pp. 47-550.

${ }^{13}$ Hans Yttemberg, "Cohabitation between two persons of same sex: a swedish story of love", en Legal recongnition of same-sex partnership. A study of Nacional, European an Internacional Law, Hart 


\section{II.I. LA DOCTRINA DE LA DISCRIMINACIÓN POR RAZÓN DE ORIENTACIÓN SEXUAL}

El TEDH también se pronunció en este ámbito, con ocasión de la prohibición de acceso de las personas homosexuales al ejército británico. Las sentencias Lustig-Prean and Beckett vs. Reino Unido y Smith and Grady vs. Reino Unido, ambas de 27 de diciembre de 1999, consideraron que la expulsión del ejército británico que sufrieron los demandantes por causa de su homosexualidad constituía una violación del artículo 8 CEDH. El gobierno británico no discutía que los homosexuales fueran menos capaces o menos valientes que los heterosexuales, o que los demandantes hubieran tenido algún problema de conducta antes de conocerse su condición. Pero alegaba que los intereses de la seguridad nacional estaban en juego y que admitir homosexuales en las fuerzas armadas tendría un significativo y negativo efecto sobre la moral de éstas. El Tribunal no acepta estos argumentos como justificación para limitar el derecho al respeto a la vida privada de los demandantes. Por el contrario, considera que la verdadera razón de su expulsión del ejército estuvo en una "actitud negativa" hacia su homosexualidad. ${ }^{14}$

No obstante, el avance más significativo en la lucha por evitar la discriminación de los homosexuales ha sido la consagración de un criterio discriminador no expreso en la enumeración realizada por el artículo 14 CEDH: la "orientación sexual". La doctrina del respeto a la vida privada como escudo protector de la homosexualidad, reiterada por el TEDH, se ve complementada y reforzada con el recurso a este criterio a partir del caso Salgueiro da Silva Mouta vs. Portugal (21 de marzo de 2000). El Tribunal resolvió que la autoridad judicial portuguesa había violado el derecho al respeto a la vida privada del demandante (art. $8.1 \mathrm{CEDH}$ ), otorgando la custodia de una hija a la madre y no a él, exclusivamente sobre la base de su homosexualidad. La sentencia manifiesta que la decisión apelada puede considerarse un supuesto de discriminación por razón de la orientación sexual del demandante, que debe entenderse incluida entre los rasgos de discriminación no expresamente enumerados en la lista abierta del artículo 14 сEDH. A partir de esta sentencia, la "discriminación por razón de

Publishing, Cambridge, 2001, pp. 127-147.

${ }^{14}$ En su voto discrepante, el juez Loucaides argumenta que el problema de la diferente acomodación de los homosexuales sí es razonable para limitar el acceso de los homosexuales a las fuerzas armadas (acceso que, recuerda, no está garantizado como derecho fundamental por el Convenio Europeo). También estima que el alegado interés de la seguridad nacional amplía el margen de apreciación de las autoridades nacionales (Cfr. F. Rey Martínez, “Homosexualidad y constitución”, Op. cit.). 
orientación sexual" ha completado en la jurisprudencia de Estrasburgo a la tradicional discriminación por razón de sexo.

En el caso Kerner vs. Austria, de 24 de julio de 2003, el TEDH consideró que la no extensión del derecho de subrogación arrendaticia al superviviente de una pareja homosexual constituía una discriminación "por razón de orientación sexual" (art. 14 CEDH) en relación con el derecho al respeto de la vida privada (art. $8.1 \mathrm{cR}$ ). El Tribunal acepta que la protección de la familia en el sentido tradicional es, en principio, una razón de peso que podría justificar una diferencia de trato, pero en las circunstancias del caso, el gobierno austriaco no aporta argumentación alguna para demostrar que esa finalidad exige no reconocer el derecho de subrogación arrendaticia a las parejas estables del mismo sexo. ${ }^{15}$

Algunos países como Holanda (1992 y 1994) y Portugal (2004) han introducido expresamente en sus constituciones la "orientación sexual" como uno de los factores discriminatorios que atentan contra el derecho a la igualdad.

\section{II.II. TranseXuales fRente al matrimonio}

La despenalización y normalización de las relaciones homosexuales corrieron paralelas al fenómeno de la transexualidad y a una progresiva aceptación de las intervenciones quirúrgicas de cambio de sexo (morfológico). ${ }^{16}$ La extensión de esta práctica encontró un eco favorable en la jurisprudencia de algunos países que han concedido efectos jurídicos a dicho cambio morfológico de sexo. ${ }^{17}$ También este fenómeno generó las

\footnotetext{
${ }^{15}$ Cuando se da una diferencia de trato por razón de orientación sexual, el TEDH exige que las autoridades nacionales aporten una justificación especialmente intensa: "particularly weighly or serious reasons", "particularly convincing and weighly reasons". En otras palabras, el TEDH aplica el principio de proporcionalidad (y no el de simple razonabilidad) o strict scrutiny test. Sobre estos conceptos, vid. F. Rey Martínez, El derecho fundamental a no ser discriminado por razón de sexo, McGraw-Hill, Madrid, 1995, pp. 48-54.

${ }^{16}$ Una buena visión del problema puede verse en E. Roca Trías, Familia y cambio social (De la "casa" a la persona), Cuadernos Civitas, Madrid, 1999, pp. 104-114.

${ }_{17}$ Un extenso tratamiento de la jurisprudencia puede verse en M. Elósegui 1txaso, La transexualidad. Jurisprudencia y argumentación jurídica, Comares, Granada 1999. Entre la jurisprudencia proclive a la concesión de efectos jurídicos al transexualismo, destaca una sentencia de 1978 del Tribunal Constitucional Federal alemán (BVerfGE 49, 286) en la que se establece: "la dignidad humana y el derecho fundamental de toda persona al libre desarrollo de su personalidad exigen que se adapte la condición personal del individuo al sexo al que pertenece conforme a su constitución psicológica y física”. En los Estados Unidos, la Corte Suprema de Nueva Jersey (M.T. v 1.T., 1976, 2. F.L.R. 2247) ha entendido que una operación de transexualidad debe considerarse un cambio de sexo a efectos jurídicos: "siempre que no contrarie algún interés social, principio de orden público o precepto moral”. Sin embargo, existen también otros ejemplos de sentencias europeas reticentes a conceder plenos efectos jurídicos al cambio
} 
primeras demandas de transexuales ante el TEDH por habérseles denegado la posibilidad de acceder al matrimonio. La jurisprudencia del Tribunal de Estrasburgo ha quedado plasmada -y permanece inalterada hasta el momento- en sus dos sentencias más representativas en este campo: las dictadas en los casos Rees y Cossey.$^{18}$ Las razones esgrimidas por el Tribunal para denegar este derecho son, en síntesis, las siguientes:

1) El derecho al matrimonio (garantizado por el artículo 12 del Convenio Europeo de Derechos Humanos) se refiere al matrimonio tradicional entre dos personas de sexo biológico opuesto. El texto de ese artículo así lo confirma, "en la medida en que el fin perseguido es la protección del matrimonio en cuanto fundamento de la familia".

2) El impedimento legal de un Estado a la celebración de matrimonio entre personas del mismo sexo biológico no puede considerarse una limitación que menoscabe la esencia del ius connubii.

3) La evolución acaecida hasta el momento en las legislaciones y la opinión pública de la mayoría de los estados miembros, "no evidencia un abandono general del concepto tradicional de matrimonio". Por eso mismo, "el mantenimiento de este concepto es razón suficiente para continuar aplicando el criterio biológico en orden a la determinación del sexo de una persona a efectos matrimoniales". ${ }^{19}$

En el contexto europeo encontramos dos tipos de planteamientos: Suecia, Alemania, Italia y Holanda han aprobado leyes internas que permiten la constancia registral del cambio de sexo, exigiendo diferentes requisitos, normalmente la sentencia judicial. A ese grupo hay que añadir España, donde antes de haber legislación al respecto, la rectificación del sexo en

de sexo. Entre ellas, en el Reino Unido: Corbett vs. Corbett (1970, 2 W. L.R. 1306, 1324); Francia: sentencias de la Corte de Casación de 16 de diciembre de 1975 (D. 1976, 397, 30 de noviembre de 1983, D. 1984, 165) y de 3 de marzo de 1987 (D. 1987, 445); Alemania: BGH, 21 de septiembre de 1971, BGHZ 57, 63; Holanda: HR, 3 de enero de 1975, NJ 1975, 187 (Cfr. R. Navarro-Valls, Matrimonio y derecho, Op. cit., pp. 93-94, n. 275).

${ }^{18}$ Vid. M. Elósegui, La transexualidad. Jurisprudencia y argumentación jurídica, Op. cit., pp. 207240; J., Escrivá lvars, Transexualismo y matrimonio, "Persona y derecho", 2 (1992), pp. 327-351; R. Navarro Valls, Matrimonio y derecho, Op. cit., pp. 98-100; N. Pérez Cánovas, Homosexualidad, homosexuales y uniones homosexuales en el derecho español, Op. cit., pp. 137-140; Y., Gómez Sánchez, El derecho a la reproducción humana, Civitas, Madrid 1994, pp. 154-155.

${ }^{19}$ Vid. M. Elósegui, La transexualidad. Jurisprudencia y argumentación jurídica, Op. cit., pp. 281332. En todo caso, cabe señalar que si la posición denegatoria del Tribunal de Estrasburgo se dirige a casos de transexualismo, unos supuestos cuya posibilidad de acceder al matrimonio podría parecer bastante clara, la posibilidad de admitir el acceso al matrimonio de dos personas del mismo sexo parece bastante alejada. No obstante estas sentencias dan lugar a interpretaciones diferentes al respecto. Pueden verse, a modo de ejemplo, las distintas visiones mantenidas por N. Pérez Cánovas, Homosexualidad, homosexuales y uniones homosexuales en el derecho español, Op. cit., pp. 133-140 y R. Navarro Valls, Matrimonio y derecho, Op. cit., pp. 98-103. 
el Registro Civil ya fue admitida por la jurisprudencia (sts de 2 de julio de 1987; 15 de julio de 1988; 3 de marzo de 1989 y 19 de abril de 1991). ${ }^{20}$ Otro grupo de países, como el Reino Unido, no admiten ese cambio en el Registro. En ninguno de estos países las rectificaciones registrales tienen eficacia respecto del matrimonio. Tan sólo en Italia, el artículo 2 de la Ley de 1992, establece que la sentencia que autoriza el cambio de sexo disuelve automáticamente el matrimonio del interesado, pero no menciona expresamente si le habilita para contraer uno con persona del sexo opuesto. En España, desde diciembre de 2005, la modificación del artículo 45 del Código Civil, a raíz de la Ley 13/2005, por virtud de la cual cualesquiera dos personas, del mismo o de distinto sexo, pueden acceder al matrimonio, ha convertido en irrelevante el debate sobre el ius nubendi de los transexuales. Algo similar ha sucedido en Holanda desde 2003.

\section{TERCERA ETAPA: EL RECONOCIMIENTO JURÍDICO DE LAS UNIONES AFECTIVAS HOMOSEXUALES}

La tercera etapa tiene como clarísima referencia la Resolución 28/1994 del Parlamento Europeo, que impulsó decididamente el reconocimiento institucional de la convivencia afectiva homosexual. Dicha resolución tuvo una notable repercusión en los países de la Unión Europea, marcando un punto de inflexión en el tratamiento del problema y propiciando el surgimiento de iniciativas legislativas dirigidas a conceder un estatuto jurídico a las uniones homosexuales. También supuso el nacimiento en la mayoría de países europeos de una serie de Registros de Uniones de hecho o Uniones Civiles (casi siempre de ámbito municipal o provincial) dirigidos a facilitar una cierta formalidad y publicidad a este tipo de uniones.

\section{III.I. La Resolución 28/1994 del Parlamento Europeo}

La Resolución del Parlamento Europeo sobre "igualdad de derechos de los homosexuales y de las lesbianas en la Unión Europea” fue aprobada el 8 de febrero de 1994. ${ }^{21}$ En un principio se planteó solicitar de la Comisión la elaboración de una "Directiva" sobre la materia, no una simple "Recomendación". La Directiva exige armonizar la legislación de los paises de

\footnotetext{
${ }^{20} \mathrm{Vid}$. Comentario a las sentencias en M. Elósegui, Op. cit., pp. 127-206.

${ }^{21}$ Se trata de la Resolución A3-0028/94. Un análisis más detallado de la misma puede verse en N. Pérez Cánovas, Op. cit., pp. 42-47; R. Navarro Valls, Op. cit., pp. 970-980.
} 
la Unión Europea, mientras que la Recomendación, que es lo que finalmente se solicitó, no es de obligado cumplimiento. Finalmente, se realiza una recomendación a los estados miembros pidiendo, entre otras cosas, la adopción de las siguientes medidas:

- Supresión de todas las disposiciones jurídicas que penalizan y discriminan las relaciones sexuales entre personas del mismo sexo.

- Poner fin a la persecución de la homosexualidad como un atentado contra el orden público o las buenas costumbres.

- Supresión de las legislaciones que permiten el almacenamiento electrónico de datos relativos a la orientación sexual de un individuo sin su consentimiento.

- Supresión de toda discriminación en el derecho laboral, penal, civil, contractual y comercial.

Quizá lo más significativo reside en su solicitud de que la futura Recomendación que se elabore ponga fin "a la prohibición de contraer matrimonio o de acceder a regímenes jurídicos equivalentes a las parejas de lesbianas o de homosexuales"; garantizando a dichas uniones "los plenos derechos y beneficios del matrimonio". También se solicita que se elimine, en los derechos nacionales, "toda restricción de los derechos de las lesbianas y homosexuales a ser padres y a adoptar o a criar niños". ${ }^{22}$

Resulta significativo el elevado número de ausencias en el Parlamento el día de la votación y el número de votos en contra y abstenciones con relación a los votos favorables a la resolución. ${ }^{23}$ Cabe suponer que estuvieran motivados por la radicalidad con la que se planteaba la equiparación de efectos entre la unión homosexual y el matrimonio. El caso es que, mientras otros aspectos de la resolución fueron asumidos por los distintos grupos parlamentarios europeos sin dificultad, el intento de equiparar las uniones de homosexuales y el matrimonio planteó desde el primer momento una fuerte resistencia en los distintos gobiernos de la Unión Europea, que todavía hoy continúa. ${ }^{24}$

${ }^{22}$ Cfr. N. Pérez Cánovas, $O p$. cit., pp. 41-47. Además del texto completo de la Resolución, puede consultarse también la Resolución del Parlamento Europeo de 13 de marzo de 1984 sobre discriminaciones sexuales en el lugar de trabajo, donde se hace una especial mención a las discriminaciones contra los homosexuales.

${ }^{23}$ En la discusión del texto de la Resolución se evidenciaron las profundas diferencias existentes entre las distintas posiciones políticas e ideológicas. La resolución, de hecho, no fue aprobada por voto masivo de los miembros de la Cámara. De los 518 diputados que forman el Parlamento Europeo, participaron en la votación solamente 273 (el 52.7\%); de ellos votaron a favor 159 (30.7\%), 98 en contra; y se registraron 18 abstenciones de diputados presentes.

${ }^{24}$ El propio Parlamento Europeo, en su Resolución de 14 de diciembre de 1994 dio un poco de marcha 
La preocupación por este tipo de discriminación se retoma en otras resoluciones posteriores, como la dictada sobre el respeto de los derechos humanos en la Unión Europea del año $1998,{ }^{25}$ o en la de 15 de enero de 2003, en la que recomienda a los estados que reconozcan el matrimonio entre personas del mismo sexo.

\section{III.II. ReCONOCIMIENTO JURídico DE LA UNIÓN AFECTIVA HOMOSEXUAL}

En el marco de la Unión Europea, podemos establecer cuatro grupos de países en función del tipo de regulación arbitrada para las parejas homosexuales: a) países carentes de regulación; b) países que han aprobado leyes de parejas de hecho; c) países en donde se han aprobado leyes de uniones civiles homosexuales; d) países que han abierto la institución matrimonial a las parejas homosexuales.

\section{III.II.I. Países SIN REgULACIÓN}

Pertenecen a este grupo Italia, Irlanda, Grecia, Austria y Luxemburgo, y el resto de los países recién llegados a la Unión Europea, excepto Hungría. ${ }^{26}$

En Italia y Grecia los sucesivos intentos de introducir reformas legales para evitar la discriminación por razón de orientación sexual (más numerosos en Italia), o las propuestas de regularización de las uniones homosexuales (muy escasas en ambos) han sido rechazadas apenas iniciada

\footnotetext{
atrás en lo propuesto en febrero. En el documento de trabajo se trataba de la equiparación de derechos entre las familias tradicionales y las alternativas o atípicas, incluyendo entre éstas a las parejas de hecho homosexuales. Finalmente, del texto definitivo fue suprimido el párrafo que decía: "la política familiar de la Unión Europea debe reconocer diferentes tipos de familias, incluyendo familias alternativas a las tradicionales, sin ninguna forma de discriminación" (Vid. D.O.C.E., n. c 18, de 23 de enero de 1995, pp. 96-99).

${ }^{25}$ D.O.C.E. de 16 de marzo de 1998, párrafos 65 a 69. En ella el Parlamento pide a todos los estados miembros "que reconozcan la igualdad de derechos de los homosexuales, especialmente mediante el establecimiento, donde aún no sea el caso, de contratos de unión civil, con vistas a suprimir todas las formas de discriminación de las que aún son víctimas los homosexuales en particular, en materia de derecho fiscal, regímenes patrimoniales, derechos sociales, etc., y que contribuyan, mediante la información y la educación, a luchar contra los prejuicios de que son objeto en la sociedad" (p. 67).

${ }^{26}$ El caso de Hungría es muy singular y significativo. Se trata de un país bastante conservador en lo moral y hostil a las organizaciones homosexuales, pero que elaboró muy rápidamente una legislación sobre uniones no casadas. Esa regulación, sin embargo, no fue el resultado de una demanda social o de reivindicaciones de los colectivos homosexuales, sino una decisión politica sorprendente de la Corte Constitucional del país. El tribunal impuso la necesidad de legislar sobre parejas no casadas, y el gobierno se apresuró a ponerla en marcha viendo en ello una oportunidad excepcional para mejorar la imagen política del país con vistas a su incorporación a la Unión Europea (Y. Vid. Merin, Equality form Same-Sex Couples, Chicago University Press, Chicago, 2002, pp.130-134).
} 
su tramitación parlamentaria. ${ }^{27}$ En los países del este de Europa, recién llegados a la Unión Europea, los colectivos homosexuales carecen de vertebración por lo que sus demandas ni siquiera están presentes en la opinión pública ni forman parte de la agenda política. El primer paso en esta dirección vendrá, seguramente, como consecuencia de la implantación de la directiva europea 1000/78 sobre protección contra la discriminación en el mercado de trabajo.

En Irlanda, en cambio, aunque tampoco existe legislación específica sobre uniones homosexuales, durante los últimos años se ha producido una verdadera revolución en el tratamiento legislativo de la homosexualidad. A partir de la resolución del caso Norris por el TEDH, se puso en marcha un vertiginoso proceso legislativo de reformas encaminado a erradicar la discriminación de los homosexuales, incluido el mercado de trabajo. ${ }^{28}$ De ahí que muchos analistas consideren inminente una regulación específica de las uniones homosexuales en este país. También cabe esperar cambios a corto plazo en Luxemburgo y Austria, en donde esa regulación ya forma parte de la agenda política de los gobiernos.

\section{III.II.II. Países oue han aprobado leyes de parejas de hecho}

No voy a detenerme ahora en analizar la compleja problemática jurídica que generan las uniones de hecho y las contradicciones y paradojas que han consagrado las diversas y heterogéneas leyes que las regulan..$^{29}$ En todo caso, se trata de disposiciones legislativas de distinto rango que, en general, regulan la situación jurídica de las uniones estables no casadas. Si hubiera que sistematizarlas de alguna manera cabría hacerlo en tres grupos: ${ }^{30}$

Leyes de cohabitación: Dentro de ellas englobamos las distintas normativas que regulan los efectos económicos derivados de una convivencia continuada de dos personas, al margen de la existencia o no de "afectividad"

\footnotetext{
${ }^{27}$ En Italia, como ha sucedido en España, se han abierto numerosos registros municipales de uniones de hecho, aunque carecen de toda eficacia y efectos.

${ }^{28}$ Vid. L. Flynn, "Same-Sex Couples and the lrish experience o Sexual Orientation Law Reform”, in Legal recongnition of same-sex partnership, A study of National, European an International Law, Hart Publishing, Cambridge, 2001, pp. 591-605.

${ }^{29}$ Remito en este ámbito a P. Talavera, La unión de hecho y el derecho a no casarse, Comares, Granada, 2000; y a mi trabajo: R. Moliner,"Las uniones homosexuales en el derecho español”, Revista de Derecho Comparado, Vol. 4, 2001,), pp. 131-170.

${ }^{30}$ Sigo en esta clasificación a K. Calvo, Ciudadanía y minorías sexuales: la regulación del matrimonio homosexual en España, Op. cit., p. 14.
} 
entre los convivientes. Este tipo de leyes se elaboraron en los países escandinavos (Dinamarca, Suecia y Noruega) durante la década de los ochenta del siglo xx y contenían disposiciones dirigidas exclusivamente a la división equitativa de los bienes (en particular vivienda y enseres domésticos) una vez disuelta la relación de las parejas no casadas. En principio, se dirigían a convivientes heterosexuales, pero a partir del año 1994 se extienden también a convivientes del mismo sexo. La peculiaridad de estas previsiones es que prescinden de la realidad afectiva de la pareja. Son normas que atienden exclusivamente a resolver las situaciones patrimoniales derivadas de la convivencia prolongada entre dos personas, sea cual sea el fundamento de esa convivencia. No se sitúan, pues, en el ámbito del derecho de familia, sino en el ámbito exclusivo del derecho patrimonial, preservando la exclusividad del matrimonio como única figura institucional reguladora de las relaciones afectivas de pareja.

Leyes de parejas de minimos: En este grupo se sitúan las leyes que regulan relaciones estables de pareja basadas en la "afectividad", aunque sin cuestionar la supremacía del matrimonio como modelo institucional paradigmático en la regulación de la convivencia afectiva de pareja. La ley húngara de uniones estables no casadas de 1996, el Pacto Civil de Solidaridad francés (PACS), aprobado en 1999, y la Ley de Uniones de Hecho portuguesa de 2001, son ejemplos palmarios de esta alternativa. También se encuadran en esta categoría las trece leyes autonómicas de parejas aprobadas hasta ahora en España, a excepción de las leyes navarra y vasca.

Estas leyes no suelen aprobarse ante la reivindicación de las parejas heterosexuales no casadas, sino como respuesta al "problema homosexual". Independientemente de cuál sea la justificación que se ofrezca ante la opinión pública, ningún gobierno ha puesto en marcha una legislación de este tipo hasta tanto no ha experimentado la presión política del colectivo homosexual. Sin embargo, son leyes que conviven con la prohibición legal de que personas del mismo sexo puedan contraer matrimonio. Esto significa que el único reconocimiento otorgado en estos países a las uniones homosexuales que deseen formalizar de algún modo su relación, es el de simples uniones de hecho.

Las leyes de parejas "de mínimos" no pretenden, pues, establecer una figura análoga al matrimonio tradicional. Su objetivo es diseñar un marco legal básico que dé respuesta a algunas reclamaciones del colectivo homosexual para evitar, precisamente, la apertura del matrimonio a las personas del mismo sexo. Este objetivo real es el que perfila sus tres principales 
características: por un lado, la universalidad; es decir, se conceptúa como unión de hecho a toda pareja, con independencia del sexo de los convivientes (aunque el verdadero objetivo sea la regulación de las uniones de personas del mismo sexo). Por otro lado, se conceden unos efectos jurídicos limitados; es decir, sólo se contempla la gestión de las relaciones patrimoniales de los convivientes, algunas disposiciones sucesorias (en muy pocas), previsiones indemnizatorias por ruptura y algunos efectos de tipo administrativo y frente a terceros. Se prevén, por tanto, medidas sobre el uso de la vivienda común, obligaciones de alimentos, reparto de los bienes y pensiones compensatorias en caso de ruptura. Son también frecuentes algunas previsiones en materia fiscal (la ley portuguesa y la francesa prácticamente equiparan a parejas casadas y no casadas en el ámbito de la tributación, no así la legislación húngara). También suelen concederse derechos en materia de seguridad social, particularmente en el caso de los empleados públicos. Ninguna de estas leyes se introduce en materia de filiación, tutela, patria potestad, adopción, naturalización de extranjeros o inseminación artificial. En tercer lugar, se impone la obligación de inscribirse en un registro; es decir, la realización de un acto constitutivo que es condición para la producción de sus efectos. Naturalmente, esto sólo se explica porque se está pensando en la pareja homosexual, pero resulta paradójico, puesto que la pareja deja de ser de hecho para convertirse en una pareja registrada (de derecho), o lo que es lo mismo, en una especie de pseudo-matrimonio de segunda categoría, con una regulación más flexible y unos efectos reducidos. ${ }^{31}$ Para salvar esta contradicción algunas leyes (la portuguesa y la asturiana) no prevén la obligatoriedad de la inscripción, pero eso genera graves problemas de seguridad jurídica: ¿puede imponerse automáticamente esa legislación a toda pareja no casada, incluso a quienes no lo deseen? En definitiva, las leyes de parejas "de mínimos" son un instrumento ambiguo y confuso que, a pesar de plantearse primordialmente como mecanismo de reconocimiento para las uniones homosexuales, resulta escasamente utilizado por ellas, como lo demuestran palmariamente las estadísticas (menos del $4 \%$ de las inscripciones en los registros son de parejas de personas del mismo sexo). ${ }^{32}$

${ }^{31}$ Vid. P. Talavera, La unión de hecho y el derecho a no casarse, Op. cit., pp. 77ss.

${ }^{32}$ Veamos como paradigma el PAcs francés. El Pacto Civil de Solidaridad, aprobado en 1999, se encuentra contemplado en el Libro 1 (bis) del Code Civil, y ofrece a cualquier pareja no casada, del mismo o de distinto sexo, la posibilidad de constituir una convivencia reconocida institucionalmente en el marco del derecho de familia, que se disuelve por matrimonio, muerte o voluntad unilateral de cualquiera de ellos y que genera los siguientes efectos: 
Leyes de parejas de máximos. Se trata de legislaciones destinadas a equiparar uniones matrimoniales y no matrimoniales (heterosexuales y homosexuales) a todos los efectos, y que plantean un panorama de modelos familiares alternativos radicalmente novedoso. En Europa apenas existen este tipo de leyes. En concreto, sólo podrían calificarse así tres de ellas: la ley holandesa de parejas registradas de 1999, y en España la ley de parejas estables de Navarra, de 2000 y la ley de parejas de hecho de Euzkadi de 2003. Todas ellas se basan sobre el reconocimiento del libre desarrollo de la afectividad y plantean el derecho a no ser discriminado ni en función de la orientación sexual ni del grupo familiar. ${ }^{33}$ Ambas leyes han justificado su maximalismo ante la imposibilidad de las personas del mismo sexo de acceder al matrimonio. Con ellas, pues, se pretenden eliminar las diferencias de trato existentes en función del estado civil de las parejas (casados o no casados) y del sexo de los componentes de la pareja (del mismo o distinto), y para ello se equiparan las uniones matrimoniales y las no matrimoniales, del mismo o distinto sexo, a todos los efectos (incluida la filiación, sucesión y adopción). De acuerdo con este planteamiento los componentes de una pareja afectiva, con independencia de su sexo, podrían optar por formalizar su relación casándose o conviviendo en unión de hecho; en ambos casos obtienen los mismos efectos, si bien bajo formalidades distintas en la constitución y disolución de su convivencia. Podrían optar también por no formalizar su situación (no registrándose), en cuyo caso, no estarían sometidos a dicho régimen legal. No cabe analizar aquí este sistema, pero baste consignar su dudosa virtualidad.

\footnotetext{
- Como deberes de los signatarios están el de alimentos y el de contribución al sostenimiento de la vida en común. Deben pactar un régimen económico, o en su defecto se les aplica el de comunidad de bienes.

- Como derechos de los signatarios:

Función pública: Traslados por destino del conviviente. Impuestos: A los tres años, tributación conjunta.

Arrendamiento: Con un año, subrogación en el contrato.

Inmigración: Con un año, se puede solicitar la residencia.

Sucesiones: Con dos años, rebaja en el impuesto de sucesiones.

Como puede verse, son unas previsiones discretas (ni siquiera se prevé la posibilidad de sucesión $a b$ intestato) y bastante alejadas del techo máximo equiparador al matrimonio, contemplado por la legislación holandesa o por las leyes de cohabitación registrada de los países nórdicos.

${ }^{33}$ Sobre la ley navarra de parejas estables no casadas, Vid. R. Moliner, "Tratamiento jurídico de las uniones de hecho", en "Curso de derecho civil valenciano", Revista General de Derecho, Valencia, 2000, pp. 1293-1297.
} 


\section{III.II.III. Países oue han APROBado LeYeS DE UNIONES CIVILES homoseXualeS}

El tercer grupo de países está constituido por aquellos que han reconocido las uniones civiles de personas del mismo sexo. Estas leyes son un producto típico de los partidos socialdemócratas del norte de Europa en alianza con las organizaciones homosexuales. La unión civil homosexual es una figura casi equiparable al matrimonio civil en cuanto a efectos, derechos y obligaciones, pero que está diseñada exclusivamente para la regulación de las parejas afectivas de personas del mismo sexo. A diferencia de las leyes de parejas de hecho, las leyes de uniones civiles no son de ámbito universal: sólo pueden acceder a ellas las parejas homosexuales. Y ello porque este tipo de unión civil nace como la alternativa homosexual al matrimonio heterosexual. Ésta es la situación de Dinamarca (1989); Noruega, Finlandia, Islandia (1993), Suecia (1995), Holanda (1998) y Alemania (2001).

La Ley danesa de Parejas Registradas, de 1989, fue la primera ley de este tipo aprobada en el mundo. Poco después se aprobaron leyes similares en el resto de los países escandinavos y Holanda. Alemania siguió también esta vía, aprobando en 2001 una ley en la que se reconocen las "comunidades de vida" formadas por parejas homosexuales. El último país europeo en incorporarse a este modelo ha sido Gran Bretaña, en diciembre de 2004, con su ley de "uniones civiles", que extiende a las parejas homosexuales registradas todos los derechos y obligaciones de los matrimonios, incluyendo la adopción, la inseminación artificial y la naturalización de extranjeros.

Es importante observar que las leyes de uniones civiles homosexuales desarrollan una terminología completamente nueva para definir el estado civil creado por la unión registrada de personas del mismo sexo. En la ley alemana se habla de "miembros de una comunidad de vida registrada" y en los países escandinavos de "miembros de una pareja registrada". Con esta nueva categoría jurídica se pretende establecer una línea de demarcación perfectamente trazada entre el estatus de estas parejas y el matrimonio civil. En Dinamarca, por ejemplo, la idea de pareja registrada fue una invención del movimiento homosexual trasladado a la legislación. En Alemania la idea de comunidad de vida fue apuntada por el Tribunal Constitucional en 1993 cuando resolvió que la Constitución alemana prohibía los matrimonios entre personas del mismo sexo. ${ }^{34}$

${ }^{34}$ Vid. K. Calvo, Ciudadanía y minorías sexuales: la regulación del matrimonio homosexual en Es- 
Las uniones civiles homosexuales suponen una casi completa equiparación de efectos con el matrimonio, excepto en los siguientes ámbitos:

- Inseminación artificial: se prohíbe a las uniones civiles acudir a la reproducción asistida como pareja.

- Nacionalidad y residencia: algunas leyes imponen a las uniones civiles requisitos que no son exigibles a los matrimonios (p. ej. un periodo mínimo de residencia en el país).

- Adopción, acogimiento, patria potestad de los hijos: Éste es el terreno más sensible y en el que leyes de uniones civiles se separan con mayor claridad del matrimonio. Únicamente la ley sueca permite a las parejas homosexuales adoptar conjuntamente (la ley del 1994 impedía explícitamente la aplicación de la legislación sobre adopción y filiación a las parejas registradas homosexuales, pero la reforma que entró en vigor en enero de 2003, ha eliminado estas restricciones). A medio camino se sitúa el caso danés, donde la reforma de 1999 concedió a las uniones homosexuales el derecho a que un miembro de la pareja pueda adoptar legalmente al hijo o hijos del otro miembro (siempre que este hijo no haya sido adoptado en un país extranjero). El proyecto de uniones civiles británico, como dijimos, contempla la posibilidad de adopción conjunta. También en Holanda, la ley de "convivencia registrada", a partir de la reforma del 2001, autoriza la adopción sobre los hijos del otro conviviente y la adopción conjunta de la pareja homosexual. La adopción sólo podrá realizarse en territorio holandés para evitar los posibles problemas jurídicos con países donde estas uniones no están reconocidas; pero Holanda acepta la adopción de un menor extranjero si el país de origen del niño no pone dificultades. ${ }^{35}$ Se incorpora también la previsión de que los hijos que nazcan en el seno de una pareja homosexual registrada (a través de fecundación artificial) sean reconocidos como descendientes de ambos. A excepción de las dos leyes de máximos españolas, ninguna otra legislación de este tipo ha sido cuestionada en sede constitucional.

\section{iV. Cuarta etapa: apertura del matrimonio a Personas del mismo SeXo}

En Europa, además de la reciente reforma producida en España (2005), solamente dos países: Holanda (2001) y Bélgica (2003), han modificado

paña, Op. cit., p. 19.

${ }^{35}$ Las organizaciones de homosexuales afirman que en Holanda hay en torno a 20,000 parejas homosexuales educando niños procedentes de relaciones anteriores de alguno de ellos. 
su legislación civil con el fin de permitir el matrimonio entre personas del mismo sexo. Ambos países lo restringen a sus nacionales y a los extranjeros que lleven, al menos, tres meses de residencia legal en ellos. Fuera del ámbito europeo, ocho provincias canadienses permiten la celebración de matrimonios homosexuales. En el ámbito estadunidense, tras los fallos judiciales contradictorios de California, el estado de Massachussets es el único que ha aprobado, en mayo de 2004, una ley que lo permite (en algunos estados como Vermont o California se reconocen efectos a las uniones de hecho homosexuales).

La técnica jurídica utilizada en estos dos países europeos resulta bastante sencilla, puesto que no existiendo definiciones constitucionales de matrimonio, todo el proceso se ventila en el ámbito de la legislación civil. No resulta complicado eliminar del concepto de matrimonio la referencia a la diferenciación de sexos, utilizando un tipo de fórmula como "la unión de dos personas, con independencia de su sexo". Partiendo de esta definición, sólo resta eliminar de un reducido número de disposiciones civiles las referencias expresas al sexo de los contrayentes (marido y mujer, esposo y esposa...), sustituyéndolas por una terminología neutra que habla de "contrayentes", "cónyuges", etc. Ésta ha sido también la técnica seguida por el legislador español.

En el debate habido en Holanda y Bélgica, además del objetivo político de equiparación de derechos entre homosexuales y heterosexuales, se ha aludido a que la apertura del matrimonio a parejas del mismo sexo resulta técnicamente más sencillo y coherente que optar por la creación de figuras paralelas a las que adjuntar efectos matrimoniales (como en Alemania). Cuando se opta por una ley específica para parejas homosexuales, el legislador se ve en la necesidad de desarrollar un nuevo y confuso estado civil (pareja homosexual registrada) y de definir su correcto acomodo en el sistema legal. Por otro lado se evita el problema de las leyes de parejas y de uniones civiles, que deben incluir complejas y farragosas enumeraciones o remisiones a legislaciones generales o especiales, que frecuentemente han de ser revisadas o completadas. ${ }^{36}$

\footnotetext{
${ }^{36}$ Merece la pena destacar una importante diferencia de planteamiento político entre los países que promueven leyes de uniones civiles o de matrimonio homosexual, por un lado, y los que se contentan con leyes de parejas de hecho, por otro. Mientras que los primeros pretenden la equiparación real entre parejas homosexuales y heterosexuales, los que apuestan por leyes de parejas de hecho tienden a reforzar la existencia de un nivel institucional exclusivo (el matrimonio heterosexual) y un nivel inferior y subordinado para regular el fenómeno homosexual. Incluso dentro de la lógica de la equiparación, quienes se decantan por las uniones civiles homosexuales se mueven en la óptica de la ley especial
} 


\section{LA ADOPCIÓN: UN PROBLEMA COMPLEJO}

La apertura del matrimonio civil a personas del mismo sexo, en realidad, sólo debe enfrentarse a un tema espinoso: la adopción de menores. ${ }^{37} \mathrm{El}$ TEDH confirmó, con ocasión de la sentencia Fretté $v s$. Francia, de 26 de febrero de 2002, ${ }^{38}$ que los estados partes del Convenio Europeo de Derechos Humanos gozan de un amplio margen de discreción para permitir o no adoptar a las uniones o matrimonios de personas del mismo sexo.

En Holanda fue a Ley 10, de 21 de diciembre de 2000 (adopción por personas del mismo sexo), la que reformó el libro I de su Código Civil, admitiendo la posibilidad de que las parejas homosexuales puedan adoptar conjuntamente con el fin de ofrecer una mejor y más coherente educación a los niños. Se exigen tres condiciones: a) llevar, al menos, tres años de convivencia (no tiene por qué ser registrada); b) un periodo de prueba de un año antes de la definitiva adopción, durante el cual se realizará un seguimiento psicosocial; c) el adoptado ha de ser nacido en Holanda. Esta misma reforma se amplió con la Ley 9, de 21 de diciembre de 2000 (de apertura del matrimonio), que modificó el mencionado libro I del Código Civil estableciendo el matrimonio como unión de dos personas con independencia de su sexo. También, cuando se trata de matrimonio entre mujeres, la legislación atribuye automáticamente la filiación a ambas "cónyuges" en caso de recurrir a la inseminación artificial. La ley belga de 2003 excluyó que los miembros del matrimonio homosexual pudieran acogerse a las disposiciones relativas a la adopción conjunta de menores, o sobre los hijos del otro "cónyuge". No obstante, a finales de 2004 se aprobó la reforma que permite adoptar a los matrimonios homosexuales. La ley británica, como dijimos, equipara completamente el matrimonio homosexual y heterosexual, incluyendo la adopción conjunta, con la sola excepción del acceso a la forma religiosa de celebración. La ley española

frente a la norma general común del matrimonio. Es decir, pretenden remarcar la singularidad del fenómeno afectivo homosexual frente a la normalidad institucional del matrimonio heterosexual. En este sentido, la mayoría de las organizaciones homosexuales europeas y españolas coinciden en rechazar la legitimidad de lo que ellos denominan "leyes especiales para homosexuales".

${ }^{37}$ Con relación al tema de la adopción por parejas homosexuales, ver el trabajo de P. Talavera, "Las uniones homosexuales frente a la adopción”, Sistema, 173, 2003, pp. 77-101.

${ }^{38}$ En su opinión discrepante, los jueces Bratza, Fuhrmann y Tuikens, consideran, no obstante, que aunque no haya un derecho a adoptar (y menos por un soltero), el derecho al respeto de la vida privada ampara esta posibilidad (porque la noción de "vida privada" es abierta y comprende el derecho a establecer y desarrollar relaciones con otros seres humanos) y, sobre todo, que las autoridades francesas habrían incurrido en discriminación prohibida por el art. 14 del cEDH en relación con el art. 8.1 CEDH (Vid. Ibidem). 
no dice nada al respecto, pero se sobreentiende que, en cuanto matrimonio, no los descarta como candidatos. Alemania y Francia han excluido esta posibilidad.

\section{Cuadro sinóptico}

\begin{tabular}{ll} 
Modelo jurídico & Países europeos \\
\hline Parejas de hecho & - Portugal (2001) \\
& - Francia (1999) \\
& - Leyes autonómicas españolas \\
& - Hungria (1996) \\
\hline Uniones civiles homosexuales & - Reino Unido (2004) \\
& - Finlandia (2001) \\
& - Alemania (2001) \\
& - Suecia (1994) \\
& - Noruega (1993) \\
& - Dinamarca (1989) \\
\hline Matrimonio civil homosexual & - España (2005) \\
& - Bélgica (2003) \\
& - Holanda (2001)
\end{tabular}

\section{Consideraciones finales}

Para concluir esta panorámica podríamos apuntar, al menos, tres consideraciones:

$1^{\circ}$ ) En el ámbito europeo se pretende defender el máximo grado de libertad e igualdad en las relaciones afectivas de pareja. Para ello, el derecho prevé lo siguiente: a) la posibilidad de acudir a un estatus matrimonial, con independencia del sexo de la pareja; b) reservar el estatus matrimonial para las parejas heterosexuales y habilitar un estatus paralelo al matrimonial para las parejas homosexuales; y c) la posibilidad de convivir en unión de hecho, con independencia de la orientación sexual de la convivencia. A cada una de estas tres opciones corresponde un estatuto jurídico acorde con la específica voluntad convivencial de la pareja. 
$2^{\circ}$ ) Casi todos los países europeos con legislación al respecto han incluido la posibilidad de adopción conjunta de menores y el acceso a las técnicas de reproducción asistida para las parejas del mismo sexo. Pero conviene recordar que la adopción no constituye un derecho de estas parejas (ni de ninguna otra), puesto que se trata de una institución esencialmente protectora, tuitiva y no declarativa de derechos (no se plantea desde la perspectiva de quienes quieren adoptar sino de quien va a ser adoptado). Por consiguiente, en sentido estricto, nadie, sea individuo o pareja (casada o no casada) tiene derecho a adoptar un menor; al contrario, es el menor quien tiene derecho a ser protegido en sus derechos fundamentales y en su desarrollo educativo por la persona o personas más idóneas. Y esa protección es la que debe garantizarse por el legislador con las medidas jurídicas pertinentes. En consecuencia, puesto que la posibilidad de adopción (o de reproducción asistida) no pueden considerarse en ningún caso como aspectos esenciales para el establecimiento y desarrollo ni de un matrimonio ni de una unión de hecho, resultaría completamente incongruente incluirlos en sus respectivas regulaciones como derechos inherentes a la pareja o reivindicarlos como tales.

$3^{\circ}$ La mayoría de los países, como hemos dicho, han entendido que la institución matrimonial debe respetar el principio heterosexual como parte de su contenido esencial y han habilitado un régimen paralelo al del matrimonio para las parejas de personas del mismo sexo que desean casarse. En nuestra opinión, esta solución es la que mejor conjuga el respeto al principio de igualdad con el respeto a la carga cultural, histórica y dogmática de la institución matrimonial. 